\title{
An Analysis of Prepositional Error Correction in TEM8 and Its Implications for FL Learning
}

\author{
Xiangyue $\mathrm{Yu}$ \\ Department of English, School of Foreign Studies, Huzhou Teachers College, Huzhou, Zhejiang Province, China
}

\begin{abstract}
As English majors, it is necessary to learn prepositions well. Nevertheless, things are not always the case. Many scholars have paid much attention to each section of TEM8, whereas this article will just focus on one issue of one section in TEM8. With view to contributing to FL learning and making English majors and non-English major learners perceive the prepositional real connotation, this article aims to analyze the incorrect use (misuse) of prepositions in proofreading \& error correction in TEM8. Firstly, the article reviews prepositions and general situations of English majors' performance in proofreading \& error correction in TEM8 and, secondly, analyzes the errors on the use of prepositions and prepositional error correction in TEM8. Finally, mainly on the basis of analyses, the author puts forward some suggestions and summarizes some beneficial implications for FL learning such as referring to the dictionary often, understanding the basic classifications of prepositions, identifying the different meaning between different prepositions, and accumulating different prepositional phrases, with the purpose of facilitating students' language internalization, enhancing their capability of language use, especially strengthening their pragmatic competence as well as developing their abilities of language cognition and critical thinking.
\end{abstract}

Index Terms-TEM8, proofreading \& error correction, prepositional error correction, analyses, implications for FL learning

\section{INTRODUCTION}

\section{A. Prepositions and Error Correction in TEM8}

Prepositions have always been widely used in English, even though the number of them is quite limited. Prepositions belong to functional parts of speech and are rather active. In English, some prepositions are among the most common words. "Linguists argue that English language is a prepositional one, which indicates that the preposition is one of the most useful and active parts of speech in English" (Li, 2007, p.11). The usage of English preposition has got great concern coming from English learners, teachers, and grammarians. As English majors, it is necessary to learn prepositions well. Nevertheless, things are not always the case. The usage of English preposition is an important aspect of testing students' English level, so many scholars choose to study this issue and write books about prepositions, which are increasingly published.

At the same time, TEM8 (Test for English Majors-Grade Eight) is one of the most crucial tests to measure English majors' study result or professional level after four years' college life. One of the necessary sections of TEM8, proofreading \& error correction, is to test students' ability of mastering multiple grammar rules and their ability to use language. From the resent years' test paper of TEM8, it is easy for us to find that prepositional error correction becomes an important knowledge point which we should attach great importance to.

\section{B. The Objective of the Study}

This article attempts to make a study on prepositions in proofreading \& error correction in TEM8. In the past, many scholars have paid much attention to each sections of TEM8, whereas this article will just focus on one issue of one section in TEM8. The author aims to analyze the incorrect use (misuse) of prepositions in proofreading \& error correction in TEM8 and, mainly on the basis of analysis, give English majors and non-English major learners some suggestions. Meanwhile, the author summarizes some beneficial implications for FL learning such as referring to the dictionary often, understanding the basic classifications of prepositions, identifying the different meaning between different prepositions, and accumulating different prepositional phrases, with the purpose of facilitating students' language internalization, enhancing their capability of language use, especially strengthening their pragmatic competence as well as developing their abilities of language cognition and critical thinking.

\section{The General Situations of English Majors’ Performance in Proofreading \& Error Correction in TEM8}

English majors didn't perform well in the section of proofreading \& error correction of TEM8. According to Li Binbin (2007), she made a survey among 60 students and found that $81.7 \%$ of the students thought that the section of proofreading \& error correction were most difficult among all the sections of TEM8. As a result, the scores students got in this section were very low, with only about 4 points out of total 10 points. 
The prepositional errors cover a large proportion of this section. According to Li Yuying (2007), she made a diagram of proofreading \& error correction from 1996 to 2007. From her diagram, we can see that the number of prepositional errors is on the top. If English majors master the preposition better, it is obvious that we can come to a conclusion that they can get an ideal score more easily.

\section{The ERror AnAlysis of Prepositional ERror Correction In TEM8}

The section of proofreading \& error correction is important inTEM8. It is integrated with multiple grammar rules and language competence. Prepositions tend to be one of the knowledge points to test students' mastery of grammar rules and English proficiency.

As we all know, TEM8 is very important for students of English major. It is a criterion to measure English majors' study results or professional level of their four years' college life, so one section of the examination, proofreading \& error correction, can reflect English majors' main errors made in their regular courses' study. Based on Comments on Past Exam Paper of TEM8 over the Years (Jin, 2008, pp.56-60), the following main errors concerning prepositional error correction are mainly from TEM8 and its simulation tests. The prepositional error in proofreading \& error correction can be categorized into three groups: 1) add preposition redundantly; 2) replace preposition incorrectly; 3 ) omit preposition improperly. The errors analyses are as follows:

\section{A. Collocating Prepositions}

In this kind of error correction, verbs should be collocated with certain prepositions to express the exact meanings. For instance, in the following sentences, "stick" collocating with preposition "to" means "not give up". We should not randomly change the fixed collocation. Take "carry on with" as an example, it is a fixed collocation which means "continue to do something", and "at the end (of)..." and "in the end" are two different fixed phrases with the same meaning. Although the meaning of these two fixed phrases is superficially same, we should consider carefully in practical use, which, in a sense, involves with the sentence's construction grammar. Please look at the following sentences:

a. Things would certainly be simpler for Americans if they stuck on to English and made the British learn Greek. ("on" $\rightarrow$ delete "on")

b. These young adults established a trend of early marriage and relatively large families that went for more than two decades and caused a major but temporary reversal of long-term demographic patterns. (add "on" after "went")

c. At the end, as everyone knows, the two countries adopted the practical and satisfactory solution of carrying with the same language as before. ("At" $\rightarrow$ "In") (add "on" between "carrying" and "with")

d. Frequently, committees rely outside experts to assist in conducting investigative hearings and to make out detailed studies of issues. (add "on" after "rely")

e. This power is usually delegated to committees-either standing committees, special committees set for a specific purpose, or joint committees consisted of members of both houses. (add "up" after "set")

\section{B. The Confusion between Transitive Verbs and Intransitive Verbs}

It is known that objects can be directly after transitive verbs, whereas intransitive verbs can not be followed by objects without any preposition. As for some verbs which can be used both as transitive verbs and intransitive verbs, we should pay more attention to their different meanings. For instance, "handle" can be used as both a transitive verb and an intransitive verb. The transitive verb "handle" means "deal with", while, as an intransitive verb, the meaning of "handle" is different. Another example is "emphasize" which is only used as a transitive verb. Let's refer to the following two sentences:

a. To handle with the crop of 1919, the government appointed the first Canadian Wheat Board. ("with" $\rightarrow$ delete "with")

b. The fact that such noises are similar on the lips of Frenchmen and Malaysians whose languages are utterly different, serves to emphasize on the fundamental difference between those noises and language proper. ("on" $\rightarrow$ delete "on")

\section{The Mixing between Different Usages}

If a verb has different usages, it is easy for us to mix them up. For example, "provide" can be either used individually, which means "supply", or used in the structure such as "provide something for somebody" and "provide somebody with something". Even the fixed phrase "provide for" means "support, stipulate or make the necessary preparation or arrangement for the future". Let's look at the sentences below:

a. Plant foods provide for 60 percent to 80 percent of the Kung diet, and no one goes hungry when hunt fails. ("for" $\rightarrow$ delete "for")

b. Today, the Internet is free resources and commercial services that provide databases and computer files with people. ("with" $\rightarrow$ "for")

c. Rivers and lakes provide us for water transport and irrigation.("for" $\rightarrow$ "with")

d. Her father always ensured she was well provided. (add "for" after "provided") 


\section{The Confusion between Simple Prepositions and Complex Prepositions}

There is a wide spectrum of opinions about the classification of English preposition. According to Quirk et al (1985), "English preposition can be classified into two types: simple preposition and complex preposition" (Min, 2004, p. 9). Simple prepositions refer to the common prepositions with only one word, while complex prepositions refer to the prepositional phrase with more than one word. For instance, "despite" and "in spite of" are synonyms; meanwhile, one is a simple preposition, the other is a complex one. We tend to get wrong in use. Please refer to the following sentence:

Interestingly, if they escape fatal infections or accidents, these contemporary aborigines live to old ages despite of the absence of medical care. ("of" $\rightarrow$ delete "of")

\section{E. The Habitual Usage}

As far as foreign language learners are concerned, what they lack is not the grammar knowledge, but the idiomatic expressions. Grammar knowledge is limited, so it is easy for them to master in a short time, while the number of idiomatic expressions is much larger, they have great difficulty in full mastery in a short period of time. So, Newmark(1982) draws a conclusion "That is why you cannot translate properly if the target language is not your language of habitual usage" (p.88). Examples are as follows:

a. The next, more subtle test of mental ability is to see what level an animal can think about something when it is not there. (add "at" between "see" and "what")

b. But in fact some grammarians have called them "empty" words as opposed with the full words. ("with" $\rightarrow$ "to")

c. They often have not been exposed against known risk factors, experts find. ("against" $\rightarrow$ "to")

d. But few of them are correlated to early childhood depression. ("to" $\rightarrow$ "with")

e. Congressional investigations therefore represent one important tool available to lawmakers to inform the citizenry and to arouse public interests in national issues. (add "of" after "citizenry", constituting "inform sb. of sth.")

\section{F. Fixed Phrases}

Any word in the fixed phrases can not be changed. For example, "at one's disposal" means "ready to assist the person concerned in any way they wish", which should not be changed in any of the words. Another two examples are as follows:

a. The English speaker has in his disposal at vocabulary and a set of grammatical rules which enable him to communicate his thoughts and feelings. ("in" $\rightarrow$ "at")

b. Although the United States maintained its dubious distinction of having the highest divorce rate in the world, the temporary decline in divorce did not occur in the same extent in Europe. ("in" $\rightarrow$ "to")

\section{G. The Slight Difference between Different Prepositions}

Different prepositions have different implied meanings. For instance, "on" and "in" are only different from the relationships of time. We can say "in the morning" but we can only say "on a cold morning". For example:

I forgot jogging in a cold morning. ("in" $\rightarrow$ "on")

However, "onto" and "on" are not the differences in time relationship, which is closely relevant with the prepositional semantic cognition. For example:

A new study uses advanced brain-scanning technology to cast light onto a topic that psychologists have bewildered over more than half a century. ("onto" $\rightarrow$ "on")

\section{IMPLICATIONS OF PREPOSITIONAL ERROR CORRECTION FOR FL LEARNING}

Actually, it is really not easy for foreign language learners to use prepositions correctly and even appropriately, for any one of the prepositions can have different usages and functions. Therefore, based on this point, we should learn to observe and use a preposition not only grammatically but also from the perspective of pragmatics and even broad stylistic context. Let's take "at" as an example. It mainly has 18 kinds of usages in most of the dictionaries. "If we come across some special prepositions like marginal prepositions, it will be more difficult to use prepositions properly" (Chi, 2003, pp. 325-349).

What should we do to solve these thorny problems? With view to contributing to FL learning and making English majors and non-English major learners perceive the prepositional real connotation and get the enlightenment, we put forward several suggestions as follows:

\section{A. Referring to the Dictionary Often}

We may as well consult the dictionary first whenever the problems on prepositions occur. The dictionary becomes a main tool for foreign language learning. We may refer to the dictionary when we come across a certain new content word, while seldom will we consult it for the empty word like preposition. As a matter of fact, most dictionaries have listed the main meanings and usages of all kinds of prepositions through impressive examples. The dictionary not only shows us the meaning of prepositions, but also gives us the common collocation of prepositions.

Beyond our expectation, prepositions in the dictionary are well introduced and interpreted in detail. Here we take Longman Dictionary of Contemporary English (Longman Publishing House, 1998, p.1087) as an example, it tells us a 
lot which will give a clear clue about preposition and make us make fewer mistakes in the test.

\section{B. Understanding the Basic Classifications of Prepositions}

What is preposition? A preposition is a word which is used to show the way in which other words are connected. Preposition may be single words such as "by, from, over, under", or they may be more complex and composed of several words such as "apart from, in front of, in spite of, instead of". Where are prepositions used? Prepositions have objects and are usually followed by a noun, pronoun, or a gerund, but sometimes prepositions' objects can also be a clause, infinitive, adjectives, and prepositional phrases, etc. In the following sentences, "in" is a preposition.

a. Write your name in the book.

b. This tea is too sweet. There is too much sugar in it.

c. There is absolutely no point in complaining.

d. I am very interested in what you have just said.

When using, we should pay attention to the following two points:

(1) A preposition + a clause as the object

When a clause is used as the preposition's object, usually this clause can't be "that-clause", in this situation, "the fact "should be added after the preposition. For example:

a. I was astonished by the fact that she had quit her job.

b. The judge paid no attention to the fact that she had just lost her husband.

However, "that-clause" can be directly followed after the preposition which expresses "except..." such as except, but. For example:

a. He has not changed at all except that he is no longer so talkative.

b. He would have helped me but that he was short of money.

(2) A preposition + prepositional phrase as the object

There are not many prepositions which belong to "a preposition + prepositional phrase as the object". Firstly, there is from, secondly there are since, until, till, etc. For example:

a. The phrase has been in wide use from before 1950's.

b. She's lived there since before the war.

c. The secret was never told until after the old man's death.

\section{Identifying Different Meaning between Different Prepositions}

What do prepositions mean? Unlike some other languages, English frequently makes use of prepositions to express basic relationships between words' relationships of time and place, for example, the following sentences are usually expressed by the use of a preposition.

a. I can see you on Monday/in August/at 8 pm/for half an hour/during the holiday, etc.

b. I'll meet you at school/in Rome/on the corner/outside the cinema/under the station clock, etc.

"The teaching of a preposition may start by introducing a visual representation of the proto-scene and emphasizing the spatial physical configuration" (Wei, 2006, p.79), but prepositions are used to express many other different kinds of relationships, for example:

a. reason-I did it because of my father/for my mother/out of duty.

b. manner-She spoke with a smile/in a soft voice.

c. means-I came by bus/on foot/in a taxi, etc.

d. reaction-I was surprised at his attitude/by his refusal, etc.

Note that a particular preposition can often be used to express more than one kind of relationships. For example, "by" can be used for the following relationships:

a. time-by next week

b. place-by the window

c. means-by working very hard

The entries for prepositions in the dictionary will show us which relationships they can be used to express.

\section{Accumulating Different Prepositional Phrases}

Prepositions are often part of fixed phrases in phrasal verbs, collocations, and idioms. Sometimes the combination of a verb with a preposition has its own particular meaning, such as "call on, look after, send for, care for, abide by, differ from, bring about" and so on. Some nouns, verbs, and adjectives are often followed by particular prepositions such as "application for, a demand for, resign from, prohibit from, afraid of, doubtful about". The prepositions which can be used with particular words are shown at the entries in the dictionary. Typical collocations (groups of words which "naturally" go together through common usage) will also be shown in the dictionary entries. These collocations often show a fixed use of prepositions such as "by the name of, in view of, with view to, in consideration of, in accordance with, beyond help, for fear of, in any event, in safe hands" (Zhang, 2004, pp. 111-145).

"Prepositions have a strong ability to collocate with nouns, verbs, and adjectives, which is a key point that makes prepositions so difficult to learn well" (Lan, 2008, pp.107-108). "A preposition can be followed by a series of syntactic units such as a noun, a non-finite clause (e.g. infinitives and gerunds), and a nominal clause" (Zhang, 2007, p.44). 
However, in this article, the author only lists some collocations as examples for English majors or non-English major learners to refer to, and only the collocation means is shown. The accumulation of different prepositional phrases will be left for them to learn and acquire during the course of their English learning.

1. The Collocation Between Prepositions and Verbs

(1) verb + sb. + of + sth.

This structure is apt to use incorrectly.

For example: You do not need to remind people their mistakes all the time. (add "of" after "people", constituting "remind sb. of sth.")

There are many phrases belonging to this structure such as "convict sb. of sth. assure sb. of sth., convict sb. of sth., convince sb. of sth., relieve sb. of sth., cure sb. of sth., rob sb. of sth.”, etc.

(2) verb + sb./sth. + of $+\mathrm{sb}$.

For example: He will agree to do what you require from him. ("from" $\rightarrow$ "of" )

This structure is often used to express requirement or hope such as "require sth. of sb., ask sth. of sb., demand sth. of sb., request sth. of sb., want sth. of sb.", etc.

(3) verb + object + from

For example: The editor deleted the last paragraph with the article. ("with" $\rightarrow$ "from")

Phrases applied to this structure are as follows:

delete from, deter from, discern from, dispense from, dissuade from, excuse from, inherit from, omit from, release from, save from, separate from, etc.

(4) verb + object + into

For example: We were deceived to believing that he could help us. ("to" $\rightarrow$ "into")

There are many phrases belonging to this structure such as "deceive into, argue into, change into, cheat into, frighten into, reason into, persuade into, scare into, shock into, terrify into, trick into", etc.

(5) verb + object + with

For example: Combine the eggs into a little flour and heat the mixture gently. ("into" $\rightarrow$ "with")

Phrases applied to this structure are as follows:

combine with, associate with, confuse with, fill with, furnish with, present with, provide with, supply with, trouble with, etc.

(6) verb + object + for

For example: The priest reproved people from not coming to church. ("from" $\rightarrow$ "for")

There are many phrases belong to this structure such as "reprove for, criticize for, denounce for, forgive for, praise for, punish for, scold for, thank for", etc.

(7) verb + object + to

For example: She attributes her success from hard work and a bit of luck. ("from" $\rightarrow$ "to" )

Phrases applied to this structure are as follows:

attribute to, admit to, compare to, confess to, limit to, restore to, etc.

(8) verb + about

For example: Let's argue with whether it is safe to go swimming in this weather. ("with" $\rightarrow$ "about")

Phrases with "about" are as follows:

argue about, bring about, come about, face about, fuss about, inquire about, leave about, lie about, roll about, set about, see about, move about, turn about, etc.

2. The Collocation Between Prepositions and Adjectives

(1) adjective + to

For example: Her latest book is quite dissimilar with her previous one. ("with" $\rightarrow$ "to")

Phrases with "to" are as follows:

dissimilar to, adequate to, advantageous to, analogous to, alive to, blind to, closed to, common to, contiguous to, deaf to, parallel to, proportional to, susceptible to, true to, convenient to sb., etc.

(2) adjective + for

For example: Only native-born citizens are eligible to the U.S. Presidency. ("to" $\rightarrow$ "for")

The adjectives which can be collocated with "for" are as follows:

eligible for, answerable for, concerned for, desperate for, distinguished for, eager for, eminent for, greedy for, notorious for, ripe for, thirsty for, etc.

(3) adjective + of

For example: Her husband felt ashamed with her behavior. ("with" $\rightarrow$ "of")

Phrases applied to this structure are as follows:

ashamed of, appreciative of, bare of, doubtful of (about), economical of, envious of, hopeful of, ignorant of, innocent of, liberal of (with), negligent of, oblivious of, profuse of, shy of, thoughtful of, tired of, tolerant of, worthy of, etc.

(4) adjective + with

For example: By 1929, Mickey Mouse was popular to children as Coca-Cola. ("to" $\rightarrow$ "with")

There are many phrases belong to this structure such as "popular with, comparable with, handy with, lined with, sick 
with, thick with, wrong with, tired with", etc.

(5) adjective + in

For example: He was unexpectedly generous to his comments on the article. ("to" $\rightarrow$ "in")

The adjective phrases with "in" are as follows:

generous in, accurate in, deficient in, engrossed in, lacking in, successful in, weak in, etc.

3. The Collocation Between Prepositions and Nouns

(1) noun + for

For example: He felt great affection to her sister. ("to" $\rightarrow$ "for")

Nouns usually collocate with "for" are as follows:

affection, ambition, anxiety, cause, consideration, charge, preference, match, provision, fancy, compensation, appetite, bent, outlet, contempt, budget, candidate, etc.

(2) noun + between

For example: He points to analogies with the two events. ("with" $\rightarrow$ "between")

These nouns can be collocated with "between" are as follows:

analogy, balance, difference, link, etc.

(3) noun + to

For example: The only access of the farmhouse is across the fields. ("of" $\rightarrow$ "to")

Nouns applied to this structure are as follows:

access, answer, appeal, approach, claim, contrast, disgrace, exception, index, preface, etc.

(4) noun + over

For example: He had an advantage upon us; He had more money. ("upon" $\rightarrow$ "over")

There are many nouns belong to this structure such as "advantage, anguish, authority, control, check, superiority, triumph, victory", etc.

(5) noun + in

For example: Public confidence on him has been restored. ("on" $\rightarrow$ "in")

The noun phrases with "in" are as follows:

confidence, delight, degree, improvement, skill, belief, defect, proficiency, etc.

\section{CONCLUSION}

All in all, as to the incorrect use (misuse) of prepositions in proofreading \& error correction in TEM8, based on the analyses, this article has given some suggestions for English majors and non-English major learners and also drawn some beneficial implications for FL learning.

In view of many practical reasons, the present study is limited to the above aspects. First, in English language, there are more than one hundred prepositions, so, due to space limitations, they will not be entirely discussed in this article. Second, there are many approaches for prepositional analysis. This study tends to show some general means to solve some problems in the examination. Third, this study is basically descriptive. Its value and application in foreign language teaching and learning have been proposed, but they have not been further examined by detailed data.

In consideration of the limitations mentioned above, we tentatively put forward some suggestions for addressing the relevant problems. First, more studies should be carried out to see whether some other analytic approaches can be used so that they can be more clear for students to understand the errors of the usage of prepositions. Second, the value and application of the present study need to be further verified with the deepening of foreign language teaching and learning. Third, the applied linguistics researchers and language teachers who are interested in this field should work together to develop more concrete, systematic and visual learning networks of prepositions in English.

\section{ACKNOWLEDGMENT}

This research was the achievement of 2010 planning fund project for the research of humanities and social sciences financed by the Ministry of Education of the People's Republic of China (Project Approval Number: 10 YJA740119), the achievement of 2013 higher education classroom teaching reform project fiscally aided by Zhejiang Province (Project Number: kg2013416), the achievement of 2014 educational science planning research project in Zhejiang Province (colleges and universities) (Project Number: 2014SCG419) and the achievement of 2013 teaching reform project financially supported by Huzhou Teachers College (Project Number: JGB13039).

\section{REFERENCES}

[1] Chi Yunbo. (2003). English Grammar Autonomous Learning. Chengdu: Sichuan People's Publishing House.

[2] Jin Shengzeng. (2008). Comments on Past Exam Paper of TEM8 over the Years. Jinan: Shandong Science and Technology Publishing House.

[3] Li Ming. A linguistic Analysis of the English Marginal Prepositions, November 2007. via CNKI database platform, http://epub.cnki.net/grid2008/detail.aspx?filename=2007174338.nh\&dbname=CMFD2007

[4] Longman Publishing House. (1998). Longman Contemporary Advanced English Dictionary. Beijing: The Commercial Press. 
[5] Lan Xiuzhen. (2008). Error Analysis of Prepositions in English Passage Error-Correction. Journal of Zhejiang Wanli University, 21(1), 107-108

[6] Li Binbin. (2007). Analysis of Proofreading \& Error Correction in TEM8 and Its Teaching Strategies. Journal of Huaihua University, 26(8), 161-163.

[7] Li Yuying. (2007). Reflective Teaching Approach of Proofreading in TEM8. Journal of Jiangxi Normal University (philosophy and social sciences edition), 40(4), 142-144.

[8] Min Juhun. A Philosophical Perspective of the Preposition, September 2004. via CNKI database platform, http://epub.cnki.net/grid2008/detail.aspx?filename=2004106721.nh\&dbname=CMFD2004.

[9] Newmark, Peter. (1982). Approaches to Translation. Oxford: Pergamon Press.

[10] Quirk, Randolph et al. (1985). A comprehensive Grammar of the English Language. London: Longman Group Limited.

[11] Wei Benli. A Functional Approach to Locative Prepositional Phrases, July 2006. via CNKI database platform, http://epub.cnki.net/grid2008/detail.aspx?filename=2007055312.nh\&dbname=CDFD2007.

[12] Zhang Yuan. A Cognitive Analysis of Prepositional Polysemy and its Pedagogical Implication, April 2007. via CNKI database platform, http://epub.cnki.net/grid2008/detail.aspx?filename=2008020777.nh\&dbname=CMFD2008 .

[13] Zhang Xinyou. (2004). College Students' English Easy Wrong Record. Wuhan: Central China Normal University Press.

Xiangyue Yu is associate professor at Department of English, School of Foreign Studies, Huzhou Teachers College, Zhejiang Province, PR China and director of the Institute of Business Foreign Languages. His research direction and academic interest are foreign linguistics and applied linguistics, and he is mainly engaged in the studies of Chinese and foreign language contrast, pragmatic rhetoric, translation and Business English. 